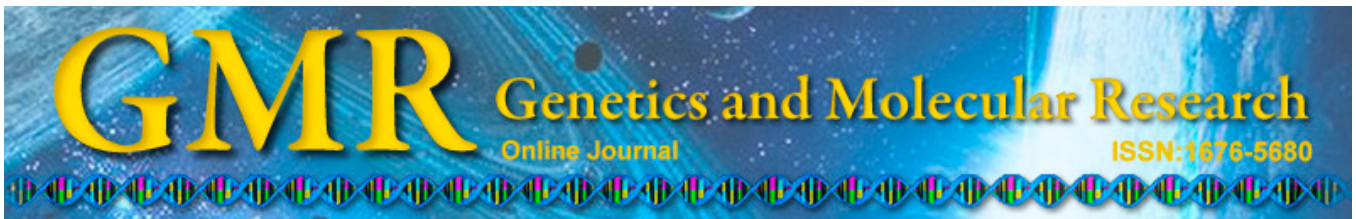

\title{
Rapid sedation induced by fentanyl combined with propofol via an intrathecal chemotherapy injection for leukemia in children
}

\author{
X. Tian' ${ }^{1}$, Y.-H. Yang ${ }^{1}$, H.-Y. Wei ${ }^{2}$, J.-Q. Lao ${ }^{2}$, H.-P. Wang ${ }^{1}$ and Y.-Y. Tian ${ }^{3}$ \\ 'Department of Hematology, Kunming Children's Hospital, Yunnan Province, \\ China \\ ${ }^{2}$ Department of Pediatrics, \\ Fourth Affiliated Hospital of Guangxi Medical University, Guangxi Province, \\ China \\ ${ }^{3}$ Department of Urology, West China Hospital, Sichuan University, \\ Sichuan Province, China \\ Corresponding author: Y.-H. Yang \\ E-mail: XinTiandoc@126.com
}

Genet. Mol. Res. 14 (2): 3687-3693 (2015)

Received July 1, 2014

Accepted September 25, 2014

Published April 17, 2015

DOI http://dx.doi.org/10.4238/2015.April.17.18

\begin{abstract}
This study explored the sedative and analgesic effects of fentanyl combined with propofol via an intrathecal chemotherapy injection for acute leukemia (acute lymphocytic leukemia or acute myelocytic leukemia) among children, to relieve pain and difficulty during intrathecal injection, improve treatment compliance, increase the success rate of single puncture, and reduce procedure failure, with the aim of developing a painless procedure for children with acute leukemia. Fifty person-times received fentanyl combined with propofol via an intrathecal chemotherapy injection among the hospitalized children with leukemia. The patients' cooperation with the procedure, response to the medication, dosages of fentanyl and propofol, reaction to the procedures, wake-up time, and changes in oxygen saturation $\left(\mathrm{SpO}_{2}\right)$, heart rate (HR), respiration, and blood pressure (BP) before, during,
\end{abstract}


and after the procedures were observed. The doctors who performed the procedures assessed the quality of sedation and analgesia. In the treatment group, the patients were quiet during the lumbar puncture and intrathecal injection, showing good sedation and analgesia. HR and respiration decreased slightly. There were no changes in $\mathrm{SpO}_{2}$ and $\mathrm{BP}$. No obvious respiratory depression occurred with proper dosages. Only a few patients showed stertorous respiration, which stopped soon after the procedures. In the control group, the patients were agitated, crying, and not cooperative before and during the procedures, which made the procedures very difficult. During intrathecal injection, pain obviously reduced and the success rate of single lumbar puncture increased. It is safe and effective to apply fentanyl combined with propofol for sedation and analgesia.

Key words: Children; Propofol; Fentanyl; Intrathecal injection

\section{INTRODUCTION}

Due to the advances in chemotherapy for leukemia, the efficacy of treatment for acute lymphocytic leukemia (ALL) and acute myelocytic leukemia (AML) has improved significantly during the last 10 years. Currently, $78-80 \%$ of ALL among children can be cured. However, the existence of the blood-brain barrier makes it difficult for medicine to pass the meninges, meaning that central nervous system leukemia (CNS-L) easily occurs, and this is an important cause for relapse. The means to change this situation is to implement chemotherapy through intrathecal injection repeatedly at different stages, with the entire treatment course requiring about 20 injections. However, this procedure causes a great deal of pain and suffering for the patients and their relatives. Furthermore, it often fails or causes injury, with delays in treatment of cerebral leukemia or multiple attempts in one procedure with difficult puncture in late chemotherapy or fear of puncture with a low success rate in treating leukemia (Barbi et al., 2005; Nagel et al., 2008; Nguyen et al., 2010). Therefore, it is necessary to develop an easily applicable method to relieve the patients' pain.

\section{MATERIAL AND METHODS}

\section{General materials}

Fifty person-times who received fentanyl combined with propofol in the intrathecal chemotherapy injection among hospitalized children aged 1-14 years with leukemia were collected from January 1, 2008 to November 30, 2009. The patients' relatives provided informed consent before the procedures.

Conditions for enrollment

1) In accordance with the criteria for diagnosis of childhood leukemia and in need of lumbar puncture and intrathecal injection.

2) The parents were informed and they agreed with the procedures. 
3) No opium was used before the procedures and the patients had no tachycardia or insufficiency of the heart, lung, liver, or kidney.

4) No obvious contradictions to operation.

Exclusion criteria included patients suffering from insufficiency of the liver or kidney or those who could not understand or comply with the study procedures.

Materials prepared included propofol, intravenous pump, electrocardiography monitor, oxygen saturation $\left(\mathrm{SpO}_{2}\right)$ monitor, pulmocardiac resuscitation bag, tracheal intubation facilities, and ventilator.

Operation methods included manipulation methods, observation index, observation methods, judgment criteria for efficacy or results, and record forms for research.

For statistical processing methods (including computing formula), the SPSS 13.0 software was used for processing data that are reported as means $\pm \mathrm{SD}$; we performed inter- and intra-group comparisons with variance analysis taking $\alpha=0.05$ as the test standard, with $\mathrm{P}<$ 0.05 indicating a difference and $\mathrm{P}<0.01$ indicating a significant difference.

\section{Application methods}

The values of blood pressure (BP), heart rate (HR), and $\mathrm{SpO}_{2}$ the day before the procedure were taken as basic values. Patients were permitted no food or drinks $1 \mathrm{~h}$ before the procedure.

2) The BP, pulse, respiration, and $\mathrm{SpO}_{2}$ were monitored during the procedure. $\mathrm{BP}$ was monitored with a non-invasive cuff.

3) In the experimental group, before intrathecal injection, fentanyl $(1-2 \mu \mathrm{g} / \mathrm{kg})$ was administered, followed by intravenous propofol (2.0-3.5 mg/kg) 3-5 min later. Propofol (50$100 \mu \mathrm{g} \cdot \mathrm{kg}^{-1} \cdot \mathrm{h}^{-1}$ ) was also delivered with a pump while the patients fell asleep, until the muscles were relaxed and eyebrow reflex disappeared. Then, lumbar puncture and intrathecal injection could be initiated. During the procedure, if the patients were agitated, additional propofol could be administered until satisfactory sedation was obtained. Intravenous medication was discontinued immediately upon termination of the procedure. The patients were transported back to the wards after they woke up, their respiration and circulation were stable and they were lucid. During the procedure, pulse, respiration, and $\mathrm{SpO}_{2}$ were monitored. Propofol was discontinued in cases of $\mathrm{SpO}_{2}<85 \%$. A pulmocardiac resuscitation bag was available for positive pressure ventilation in case of significant respiration depression.

Assistant ventilation was necessary in case respiration depression occurred, with a progressive decrease of $\mathrm{SpO}_{2}$, cyanosis, and decreased respiration.

The observation index included degree of anesthesia, HR, changes in respiration, wake-up time (response to questions means lucid, wake-up time means duration between time when the propofol was discontinued and time when the patients were lucid), and presence or absence of agitation. Satisfactory degree of sedation and analgesia was assessed by the doctors who performed the procedures.

\section{Evaluation of the effect of analgesia}

\section{Criteria for efficacy}

Significantly effective: the patients fell asleep and the procedures could be completed 
successfully; the monitoring indices, e.g., respiration, HR, and BP were stable; the patients did not feel pain [Face, Legs, Activity, Cry, Consolability (FLACC) score 0] and were cooperative during the procedures (Ramsay Sedation Score 4 or greater).

Effective: the patients did not fall asleep, but the procedures could be completed; the monitoring indices, e.g., respiration, HR, and BP were stable; the patients felt pain (FLACC score 1 to 3) and were not very cooperative during the procedures (Ramsay Sedation Score 2 or 3).

Ineffective: the procedures could not be completed; the patients felt pain (FLACC score 4 or greater) and were not cooperative during the procedures (Ramsay Sedation Score 1).

\section{Effect of analgesia}

The observation index included cooperation before the procedure; response to medication; HR, $\mathrm{BP}$, respiration, and $\mathrm{SpO}_{2}$ before, during, and after the procedure; dose of propofol, satisfaction with sedation and analgesia; wake-up time (response to questions means lucid, wake-up time means duration between the time when the propofol was discontinued and time when the patients were lucid). Satisfactory degree of sedation and analgesia was assessed by the doctors who performed the procedures.

The experimental group (fentanyl and propofol group) did not demonstrate restlessness or crying, while these behaviors were observed in $78 \%$ of the control group. In addition, the experimental group showed good compliance and rapid recovery, with the longest recovery time being $5 \mathrm{~min}$, while the control group demonstrated poor compliance.

In summary, our results show that there was no agitation or crying observed after injection of fentanyl and propofol, and the patients demonstrated good compliance and quick wake-up, with the longest observed recovery time being $5 \mathrm{~min}$ (Table 1). and gender.

There were no significant differences in patient demographics such as age, weight,

\begin{tabular}{|c|c|c|c|c|c|c|c|c|c|c|c|}
\hline \multirow[t]{2}{*}{ Person-times } & \multicolumn{5}{|c|}{ Response in procedure (person-times) } & \multicolumn{3}{|c|}{ Wake-up time (min) } & \multicolumn{3}{|c|}{ Sedation quality } \\
\hline & Agitation & Forced & Cried & $\begin{array}{l}\text { Heavy } \\
\text { sweaty }\end{array}$ & $\begin{array}{c}\text { Res. } \\
\text { depression }\end{array}$ & 1 & 3 & 5 & $\begin{array}{c}\text { Very } \\
\text { satisfied }\end{array}$ & Satisfied & $\begin{array}{c}\text { Not } \\
\text { satisfied }\end{array}$ \\
\hline $\begin{array}{l}\text { Experimental group } \\
56 \text { times }\end{array}$ & 0 & 0 & 0 & 0 & 0 & $5(9 \%)$ & $37(66 \%)$ & $14(25 \%)$ & $48(85 \%)$ & $8(14 \%)$ & 0 \\
\hline $\begin{array}{l}\text { Control group } \\
23 \text { times }\end{array}$ & $18(78 \%)$ & $16(69 \%)$ & $16(69 \%)$ & $15(65 \%)$ & 0 & 0 & 0 & 0 & 0 & $7(30 \%)$ & $16(70 \%)$ \\
\hline
\end{tabular}

\section{Comparison of $B P$, respiration, and $H R$}

Measurements taken before and during the procedures showed that BP decreased during the procedure, HR increased mildly, and there were no significant changes in respiration. There were no significant differences between the two groups (Tables 2 and 3 ). 
Table 2. Changes in BP during the procedure (means $\pm \mathrm{SD} \mathrm{mmHg}$ ).

\begin{tabular}{|c|c|c|c|c|c|c|}
\hline \multirow[t]{2}{*}{ Person-times } & \multicolumn{3}{|c|}{ Systolic pressure } & \multicolumn{3}{|c|}{ Diastolic pressure } \\
\hline & Pre-op & Intra-op & Post-op & Pre-op & Intra-op & Post-op \\
\hline \multicolumn{7}{|l|}{ Experimental group } \\
\hline 56 times & $87.12 \pm 11.05$ & $82.14 \pm 12.01 *$ & $83.24 \pm 10.03$ & $46.21 \pm 8.03$ & $42.76 \pm 3.32$ & $43.18 \pm 7.61$ \\
\hline \multicolumn{7}{|l|}{ Control group } \\
\hline 23 times & $86.36 \pm 9.05$ & $95.56 \pm 9.31 * *$ & $85.27 \pm 8.13$ & $52.24 \pm 11.03$ & $53.25 \pm 9.12 *$ & $51.36 \pm 7.03$ \\
\hline
\end{tabular}

Compared with those before examination, $* \mathrm{P}<0.05, * * \mathrm{P}<0.01$.

Table 3. Changes in respiration and heart rate (means \pm SD).

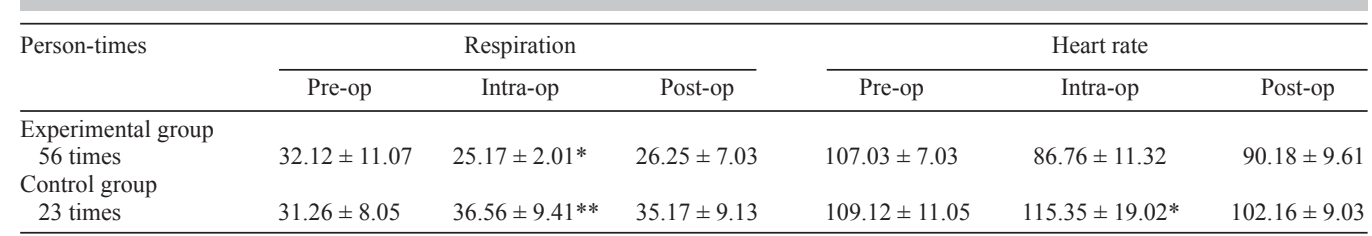

Compared with those before examination, $* \mathrm{P}<0.05, * * \mathrm{P}<0.01$.

\section{DISCUSSION}

Due to the progress in chemotherapy for leukemia, the efficacy of treatment for ALL and AML has improved significantly during the last 10 years. While currently $78-80 \%$ of ALL among children can be cured, the presence of the blood-brain barrier makes it difficult for the medicine to pass the meninges, thus making CNS-L frequent and an important cause of relapse. The solution to this problem is the repeated intrathecal injection of chemotherapy drugs at different stages, about 20 times altogether during the entire treatment. However, this procedure causes significant pain and suffering for the patients and their relatives. Furthermore, it often fails or causes injury with delays in treatment of cerebral leukemia or multiple attempts in one procedure with difficult puncture in late chemotherapy or fear of puncture with a low success rate in treating leukemia.

It is necessary to implement sedation and analgesia via intrathecal chemotherapy injection to relieve fear and pain and improve control over activities. Otherwise, forced pressure on children related to the procedure will cause pain and nervousness for the patients and the relatives, which are not good for the treatment. Furthermore, it is useless to console the children after the procedure (Reeves et al., 2004; Lundeberg and Roelofse, 2011; Masala et al., 2011).

The alternatives for sedation and analgesia (Barbi et al., 2005; Yousef and Amr, 2010; Borendal Wodlin et al., 2011) include local anesthesia (lidocaine, amethocaine hydrochloride mucilage) and general anesthesia (diazepam, midazolam, aethocaine, propofol, sevoflurane). Intravenous medication may cause safety problems, such as respiration depression (Yaster and Nichols, 2001; Mantadakis et al., 2009; Batra et al., 2010), while local anesthesia in lumbar punctures may not work due to patients' crying (Committee on Drugs and American Academy of Pediatrics, 2002; Draisci et al., 2009; Baniadam et al., 2010; Shadangi et al., 2011). Propofol is an intravenous anesthetic commonly used clinically, which is quickly effective and easily controlled. Patients wake up very soon after administration of the medicine is discontinued. It is broadly used for sedation in the pediatric intensive care unit (Gottschling et al., 2005; 
Leino et al., 2009; Kearns et al., 2011; Rebel et al., 2011) and it is also used in adults for anesthesia. It is also reportedly used in the removal of tracheal foreign bodies among children and many types of superficial operations. However, we could not find reports of propofol being used via intrathecal chemotherapy injection in ALL among children, either in China or in other countries.

With propofol, it is easy to adjust the depth of sedation and to both quickly pass out and wake up soon after the medicine is discontinued. There is no significant accumulation with administration over a long period of time. However, the medication may depress circulation and respiration. A small dosage of fentanyl can reduce the required dose of propofol, thus decreasing the depression of circulation and improving sedation and thereby helping to implement invasive procedures. Our findings showed that the use of propofol combined with a small dose of fentanyl led to good results in children receiving intrathecal injections. The method is safe and effective for sedation, and non-narcotic medical professionals can easily grasp the usage and dosage of the medicine.

\section{ACKNOWLEDGMENTS}

Research supported by the Scientific Research Foundation of Yunnan Province, China (\#2010EZ246).

\section{REFERENCES}

Baniadam A, Afshar FS and Ahmadian F (2010). Analgesic effects of tramadol hydrochloride administered via caudal epidural injection in healthy adult cattle. Am. J. Vet. Res. 71: 720-725.

Barbi E, Badina L, Marchetti F, Vecchi R, et al. (2005). Attitudes of children with leukemia toward repeated deep sedations with propofol. J. Pediatr. Hematol. Oncol. 27: 639-643.

Batra YK, Rakesh SV, Panda NB, Lokesh VC, et al. (2010). Intrathecal clonidine decreases propofol sedation requirements during spinal anesthesia in infants. Paediatr. Anaesth. 20: 625-632.

Borendal Wodlin N, Nilsson L and Kjølhede P (2011). The impact of mode of anaesthesia on postoperative recovery from fast-track abdominal hysterectomy: a randomised clinical trial. BJOG 118: 299-308.

Committee on Drugs and American Academy of Pediatrics (2002). Guidelines for monitoring and management of pediatric patients during and after sedation for diagnostic and therapeutic procedures: addendum. Pediatrics 110: 836-838.

Draisci G, Frassanito L, Pinto R, Zanfini B, et al. (2009). Safety and effectiveness of coadministration of intrathecal sufentanil and morphine in hyperbaric bupivacaine-based spinal anesthesia for cesarean section. J. Opioid Manag. 5: $197-202$.

Gottschling S, Meyer S, Krenn T, Reinhard H, et al. (2005). Propofol versus midazolam/ketamine for procedural sedation in pediatric oncology. J. Pediatr. Hematol. Oncol. 27: 471-476.

Kearns RJ, Macfarlane AJ, Anderson KJ and Kinsella J (2011). Intrathecal opioid versus ultrasound guided fascia iliaca plane block for analgesia after primary hip arthroplasty: study protocol for a randomised, blinded, noninferiority controlled trial. Trials 12: 51.

Leino T, Viitamaa T, Haapalinna A, Lehtimäki J, et al. (2009). Pharmacological profile of intrathecal fadolmidine, a alpha2-adrenoceptor agonist, in rodent models. Naunyn Schmiedebergs Arch. Pharmacol. 380: 539-550.

Lundeberg S and Roelofse JA (2011). Aspects of pharmacokinetics and pharmacodynamics of sufentanil in pediatric practice. Paediatr. Anaesth. 21: 274-279.

Mantadakis E, Katzilakis N, Foundoulaki E and Kalmanti M (2009). Moderate intravenous sedation with fentanyl and midazolam for invasive procedures in children with acute lymphoblastic leukemia. J. Pediatr. Oncol. Nurs. 26: 217-222.

Masala S, Nano G, Mammucari M and Simonetti G (2011). Kummel disease treatment by unipedicular vertebral augmentation using curved injection cannula. Cardiovasc. Intervent. Radiol. 34: 1014-1020.

Nagel K, Willan AR, Lappan J, Korz L, et al. (2008). Pediatric oncology sedation trial (POST): A double-blind randomized study Pediatr. Blood Cancer 51: 634-638.

Nguyen M, Vandenbroucke F, Roy JD, Beaulieu D, et al. (2010). Evaluation of the addition of bupivacaine to intrathecal 
morphine and fentanyl for postoperative pain management in laparascopic liver resection. Reg. Anesth. Pain Med. 35: 261-266.

Rebel A, Sloan P and Andrykowski M (2011). Retrospective analysis of high-dose intrathecal morphine for analgesia after pelvic surgery. Pain Res. Manag. 16: 19-26.

Reeves ST, Havidich JE and Tobin DP (2004). Conscious sedation of children with propofol is anything but conscious. Pediatrics 114: e74-e76.

Shadangi BK, Garg R, Pandey R and Das T (2011). Effects of intrathecal midazolam in spinal anaesthesia: a prospective randomised case control study. Singapore Med. J. 52: 432-435.

Yaster M and Nichols DG (2001). Pain management in the critically ill child. Indian J. Pediatr. 68: 749-769.

Yousef AA and Amr YM (2010). The effect of adding magnesium sulphate to epidural bupivacaine and fentanyl in elective caesarean section using combined spinal-epidural anaesthesia: a prospective double blind randomised study. Int. J. Obstet. Anesth. 19: 401-404. 